\title{
PERANCANGAN SISTEM INFORMASI AKADEMIK BERBASIS WEB PADA SD ISLAM LUQMANUL HAKIM BEKASI
}

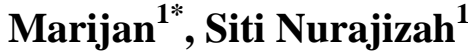 \\ Program Studi Sistem Informasi, STMIK Nusa Mandiri Jakarta \\ Email : *marijanerni512@gmail.com
}

\begin{abstract}
Abstrak: Pesatnya perkembangan teknologi informasi saat ini membawa manusia ke dalam dunia baru. Dunia dimana komunikasi mempunyai peran sangat penting dalam setiap aspek kehidupan, salah satunya dalam dunia pendidikan. Sekolah sebagai instansi pemerintah di bidang pendidikan banyak melakukan pengolahan data, baik data siswa, data guru maupun data staff sekolah. Data tersebut selain banyak juga bisa berubah sewaktu-waktu sehingga penyimpanan dan administrasi data harus dilakukan dengan baik dan update. SD Islam Luqmanul Hakim adalah sebuah yayasan pendidikan Islam yang berlokasi di desa Suka Sejati, kecamatan Cikarang Selatan, kabupaten Bekasi. SD ini masih tergolong baru dan saat ini masih menggunakan cara manual dalam pengolahan data akademik dimana pencatatan masih menggunakan microsoft office (word dan excel) dan disimpan dalam lemari buku. Sistem informasi akademik merupakan salah satu solusi untuk memberikan sebuah informasi secara cepat, tepat dan akurat. Sistem informasi akademik berbasis web sangat berguna dalam memberikan kemudahan baik kepada guru ataupun siswa. Metode yang digunakan pada pengembangan sistem informasi akademik ini menggunakan model prototype. Sistem Informasi Akademik Berbasis Web merupakan solusi yang tepat untuk mewujudkan sebuah sistem informasi yang efektif dan efisien.
\end{abstract}

Kata Kunci: Sistem, Informasi, Akademi, Website

\begin{abstract}
The rapid development of information technology today brings people into a new world. The world where communication has a very important role in every aspect of life, one of them is in the world of education. Schools as government agencies in the field of education do a lot of data processing, both student data, teacher data and school staff data. The data in addition to much can also change at any time so that data storage and administration must be done well and updated. Luqmanul Hakim Islamic Elementary School is an Islamic education foundation located in Suka Sejati village, South Cikarang sub-district, Bekasi district. This elementary school is still relatively new and currently uses manual methods in processing academic data where the recording is still using Microsoft Office (Word and Excel) and stored in a bookshelf. Academic information system is one solution to provide information quickly, precisely and accurately. Web-based academic information systems are very useful in providing convenience to both teachers and students. The method used in the development of academic information systems uses a prototype model. Web-Based Academic Information System is the right solution to create an effective and efficient information system.
\end{abstract}

Keywords: System, Information, Academic, Website 
DOI: https://doi.org/10.33330/jurteksi.v6i1.399

Available online at http://jurnal.stmikroyal.ac.id/index.php/jurteksi

\section{PENDAHULUAN}

Pesatnya perkembangan teknologi informasi saat ini membawa manusia ke dalam dunia baru. Dunia dimana komunikasi mempunyai peran sangat penting dalam setiap aspek kehidupan, seperti di bidang ekonomi, hiburan dan bidang lainnya termasuk dalam dunia pendidikan.

Sekolah sebagai instansi pemerintah di bidang pendidikan banyak melakukan pengolahan data, baik data siswa, data guru maupun data staff sekolah. Data tersebut selain banyak juga bisa berubah sewaktu-waktu sehingga penyimpanan dan administrasi data harus dilakukan dengan baik dan update.

Saat ini sudah banyak sekolah mulai tingkat SMP sampai Perguruan Tinggi memiliki website sekolah yang digunakan untuk memperkenalkan profil sekolah SD Islam Luqmanul Hakim adalah sebuah yayasan pendidikan Islam yang berlokasi di desa Suka Sejati, kecamatan Cikarang Selatan, kabupaten Bekasi. SD ini masih tergolong baru dan saat ini masih menggunakan cara manual dalam pengolahan data akademik dimana pencatatan masih menggunakan microsoft office (word dan excel) dan disimpan dalam lemari buku. Sekolah ini membutuhkan sebuah website akademik untuk pengolahan informasi akademik seperti pengolahan data siswa, data guru, data nilai siswa, data kegiatan sekolah dan lain-lain yang bisa diakses dengan lebih cepat dan mudah [1] Menyatakan bahwa pengolahan data siswa yang banyak merupakan kegiatan yang cukup menghabiskan waktu dan energi bagi pihak administrasi. Padahal kegiatan pengolahan data merupakan kegiatan yang sangat penting untuk mengetahui data para siswa, baik dari nilai maupun data pribadi. Pengolahan yang dilakukan pada SD Negeri 29 Jakarta masih konvensional, sehingga apabila orang tua ingin mengetahui mengenai nilai siswa atau ingin mengetahui informasi terbaru dari sekolah, siswa harus menghubungi gurunya terlebih dahulu. Selain itu proses pencarian data nilai siswa membutuhkan waktu yang lama karena harus mencari dan membuka berkasberkas terlebih dahulu.

[2] Pada saat ini semua kegiatan akademik di sekolah SMA Kristen 1 Tomohon dilakukan secara manual dan komputer yang ada hanya digunakan untuk membuat laporan. Adapun kegiatan akademik di SMA Kristen 1 Tomohon meliputi proses memasukkan data pegawai, guru, dan data siswa, proses memasukkan data jadwal mata pelajaran, proses memasukkan nilai ujian serta rekapan raport siswa. Guna mendapatkan informasi yang tepat dan akurat dalam pengaksesan datanya, maka informasi dapat dirangkum dalam sebuah sistem informasi berbasis web. Melihat keadaan sekarang yang ada di SMA Kristen 1 Tomohon dengan sistem akses manual, maka perlu dibangun sebuah sistem informasi yang dapat mempermudah proses akses data tersebut pada database.

[3] Menuliskan bahwa sistem informasi administrasi akademik akan dapat memberikan manfaat dalam dunia pendidikan terutama dalam mempermudah dan meningkatkan kinerja pendidikan, mempertinggi efektifitas dan produktifitas pendidikan, lebih fleksibel dan mempermudah pengoperasian pendidikan. 
DOI: https://doi.org/10.33330/jurteksi.v6i1.399

Available online at http://jurnal.stmikroyal.ac.id/index.php/jurteksi

\section{METODE}

Teknik Pengumpulan Data:

A. Observasi

Teknik untuk mendapatkan data dengan cara melakukan pengamatan dan pencatatan secara sistematis terhadap unsur-unsur penting yang berguna untuk penelitian. Penulis melakukan observasi langsung ke SD Islam Luqmanul Hakim yang berada di Kp. Nambo RT 12 RW 06 Desa Suka Sejati Kec. Cikarang Selatan Kab Bekasi Jawa Barat.

B. Wawancara

Penulis melakukan wawancara dengan langsung dengan kepala sekolah SD Islam Luqmanul Hakim, Bapak M. Nana Nuraffandi, S.Pd.I untuk mengetahui gambaran sistem berjalan di sekolah tersebut.

C. Studi Pustaka

Penulis menghimpun informasi yang sesuai dengan topik atau masalah yang sedang diteliti, informasi tersebut diperoleh dari sumber-sumber tertulis baik secara cetak maupun elektronik. Dengan metode ini penulis menggambarkan masalah secara jelas untuk acuan materi skripsi.

Model Pengebangan Sistem

Dengan metode prototyping ini pengembang dan pelanggan dapat saling berinteraksi selam proses pembuatan sistem. Sering terjadi seorang pelanggan hanya mendefinisikan secara umum apa yang dibutuhkan, pemrosesan dan datadata apa saja yang dibutuhkan. Sebaliknya disisi pengembang kurang memperhatikan efisiensi algoritma. Kemampuan sistem operasi dan interface yang menghubungkan manusia dengan komputer.

Dalam Perancangan Sistem Informasi ini, penulis menggunakan model pengembangan sistem Prototype. Menurut McLeod dalam Purwanto dan Abdul [4] Prototype dedifinisikan sebagai alat yang memberikan ide bagi pembuat (developer system) maupun pemakai (user) tentang cara sistem berfungsi dalam bentuk lengkapnya dan proses untuk meghasilkan prototype disebut prototyping.

\section{HASIL DAN PEMBAHASAN}

Use case

Use case diagram ini menggambarkan sistem informasi akademik di SD Islam Luqmanul Hakim, yaitu pengelolaan siswa, guru dan adminstrator, berikut gambarannya:

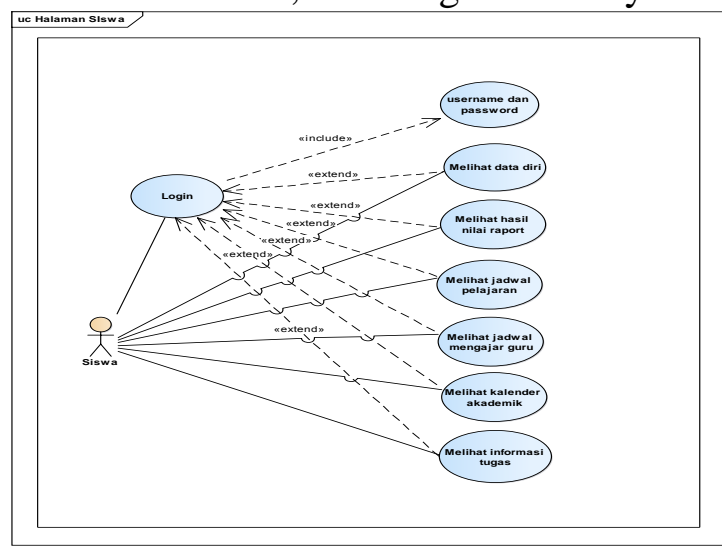

Gambar 1.Use Case Diagram Halaman Siswa

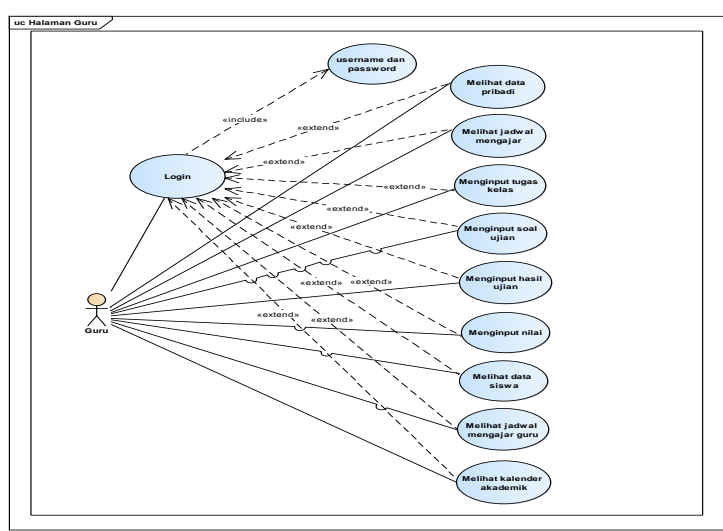

Gambar 2.Use Case Diagram Halaman Guru 
Vol. VI No. 1, Des 2019, hlm. 71 - 78

DOI: https://doi.org/10.33330/jurteksi.v6i1.399

Available online at http://jurnal.stmikroyal.ac.id/index.php/jurteksi

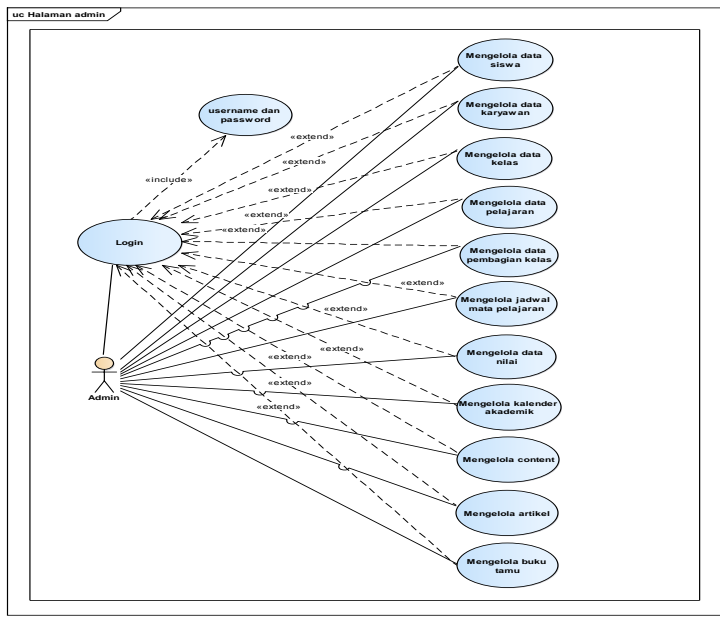

Gambar 3.Use Case Diagram Halaman

Admin

Activity Diagram

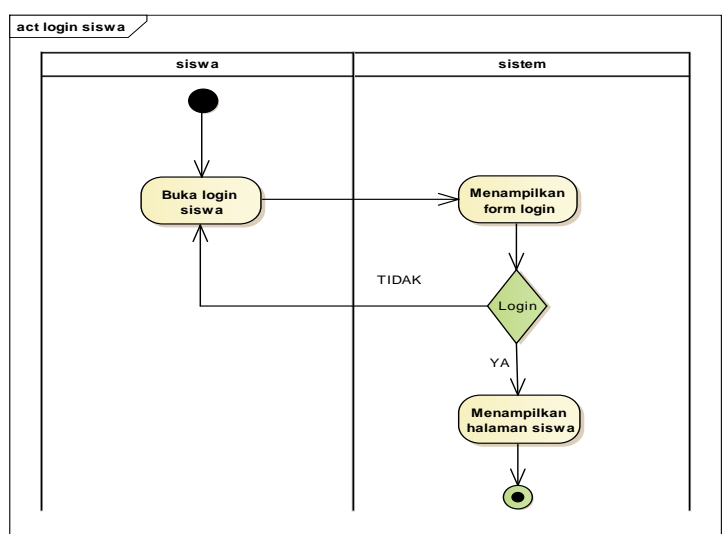

Gambar 4. Activity Diagram Login

Siswa

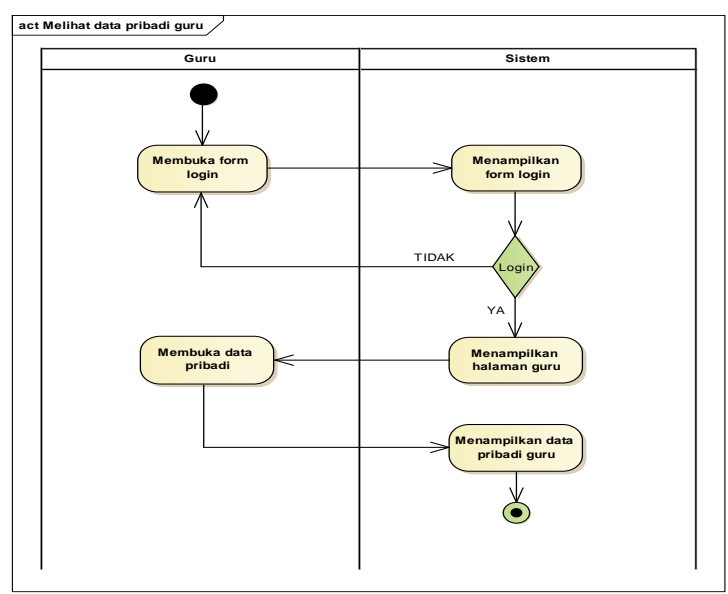

Gambar 5. Activity Diagram Guru

Melihat Data Pribadi

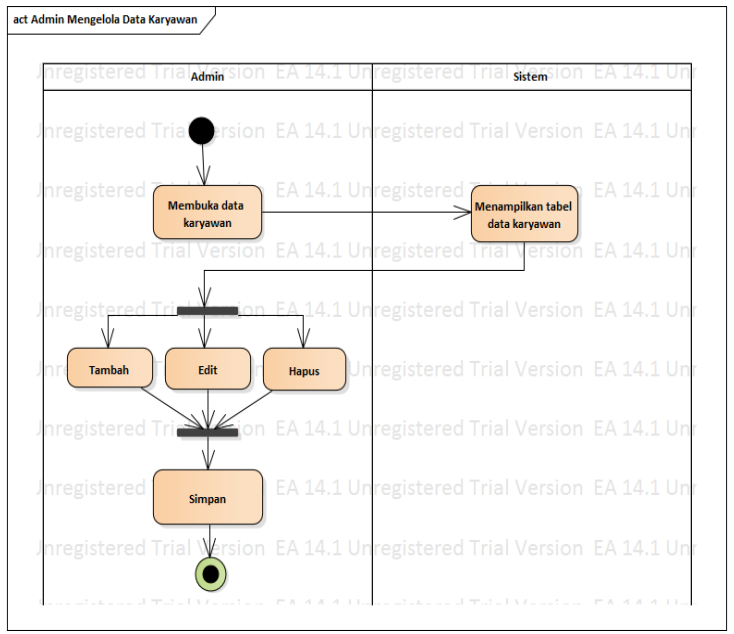

Gambar 6. Activity Diagram Admin Mengelola Data Karyawan

ERD (Entity Relationship Diagram)

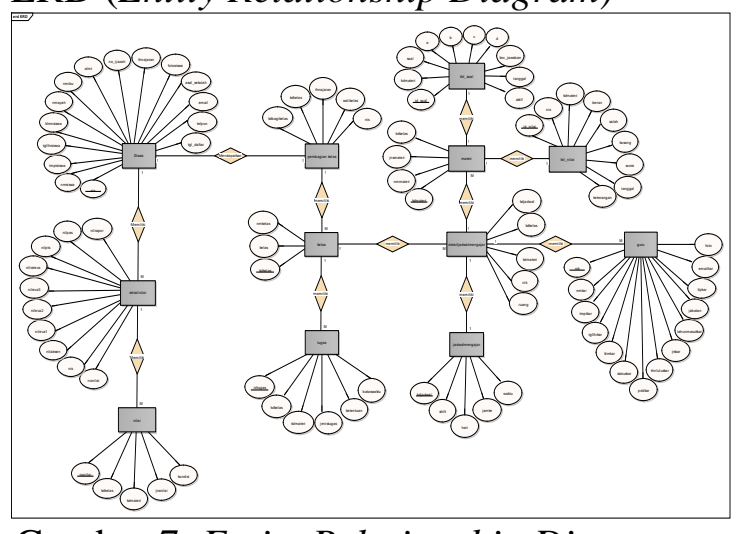

Gambar 7. Entity Relationship Diagram (ERD)

\section{LRS (Logical Relational Structure)}

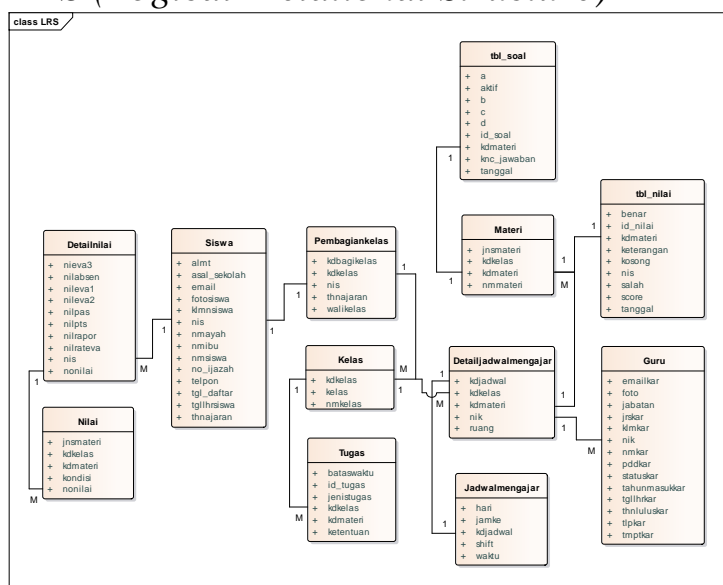

Gambar 8. Logical Relational Structure (LRS) 
DOI: https://doi.org/10.33330/jurteksi.v6i1.399

Available online at http://jurnal.stmikroyal.ac.id/index.php/jurteksi

\section{Implementasi Program}

Halaman Index Website

Halaman Index website, terdiri dari menu Home, PPDB (Penerimaan Peserta Didik Baru), Profil Sekolah, Galeri, Kalender Akademik, Artikel, Buku Tamu, Login Guru, dan Login Siswa.

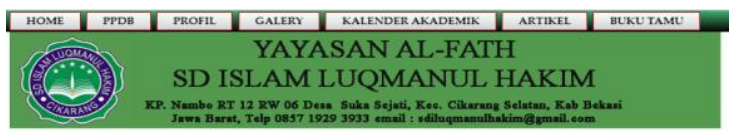

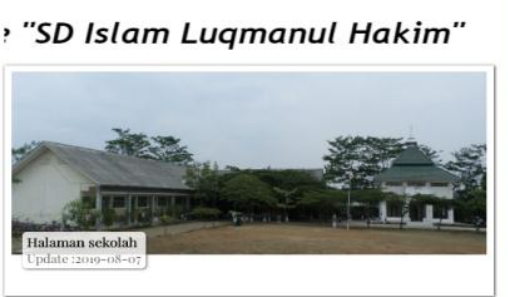

Gambar III.9

Halaman Index Website

a. Halaman PPDB

Halaman PPDB (Penerimaan Peserta Didik Baru) berisikan formulir pendaftaran calon peserta didik baru.

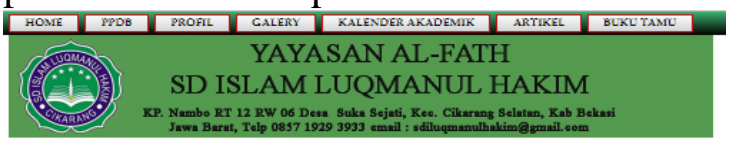

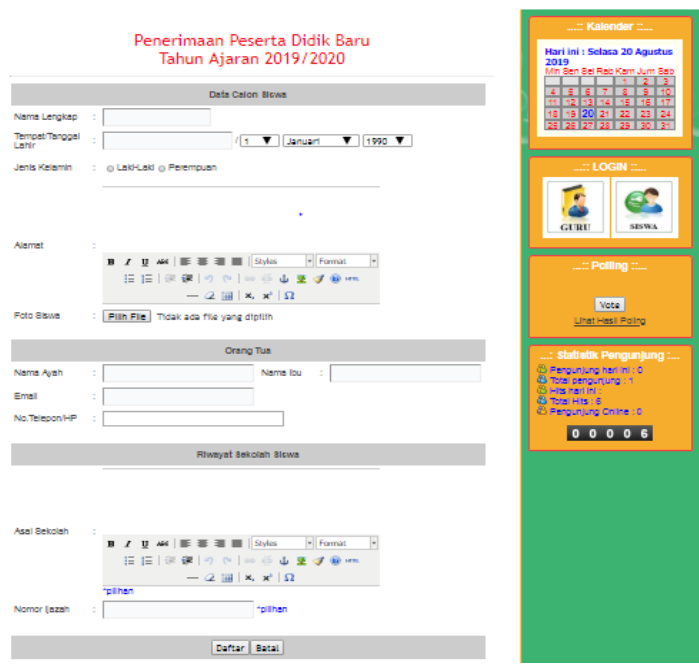

Gambar 10. Halaman PPDB b. Halaman Kalender Akademik

Halaman ini menampilkan informasi kalender akademik Sekolah SD Isalm Luqmanul Hakim

\begin{tabular}{|c|c|c|c|c|c|c|}
\hline HOME & PPDB & PROFIL & GALERY & KALENDER AKADEMIK & ARTIKEL & BUKU TAMU \\
\hline & \multicolumn{6}{|c|}{ YAYASAN AL-FATH } \\
\hline & \multicolumn{6}{|c|}{ SD ISLAM LUQMANUL HAKIM } \\
\hline & & \multicolumn{5}{|c|}{ 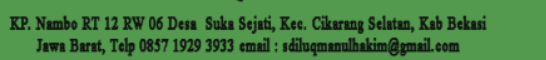 } \\
\hline
\end{tabular}
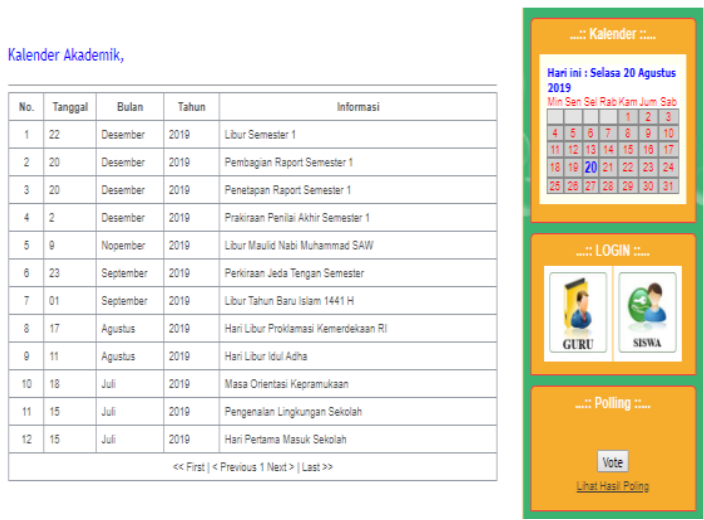

Gambar 11. Halaman Kalender

Akademik

c. Halaman Artikel

Halaman Artikel menampilkan informasi artikel sekolah

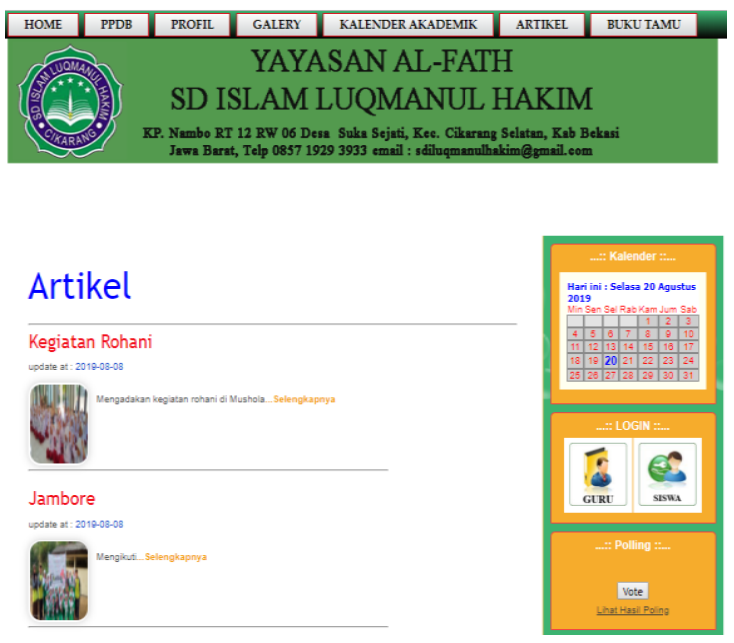

Gambar III.12 Halaman Artikel 
DOI: https://doi.org/10.33330/jurteksi.v6i1.399

Available online at http://jurnal.stmikroyal.ac.id/index.php/jurteksi

\section{d. Halaman Buku Tamu}

Halaman ini berisikan formulir pengunjung yang membuka website sekolah
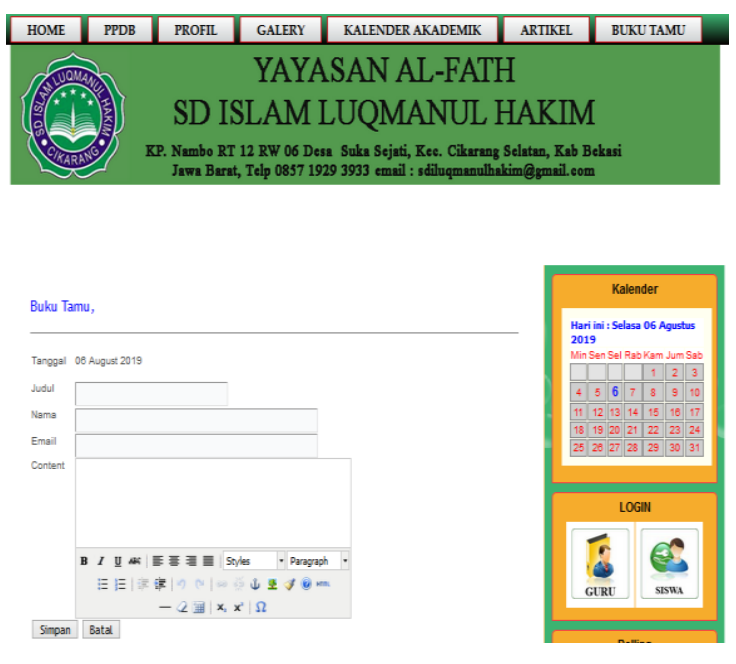

Gambar III.13 Halaman Buku Tamu

\section{e. Form Login Guru}

Guru melakukan login pada form login dengan memasukkan username dan password sebelum masuk ke halaman Home guru.

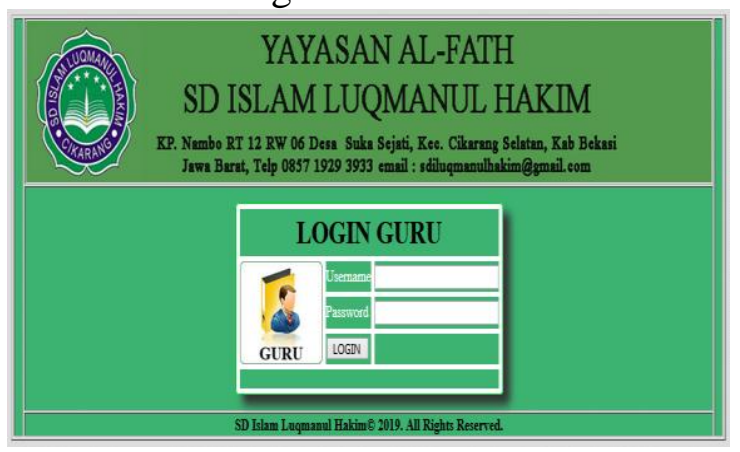

Gambar III.14 Halaman Login Guru

f. Halaman Home Guru

Halaman home guru menampilkan beberapa menu yang bisa diakses dan dikelola oleh guru

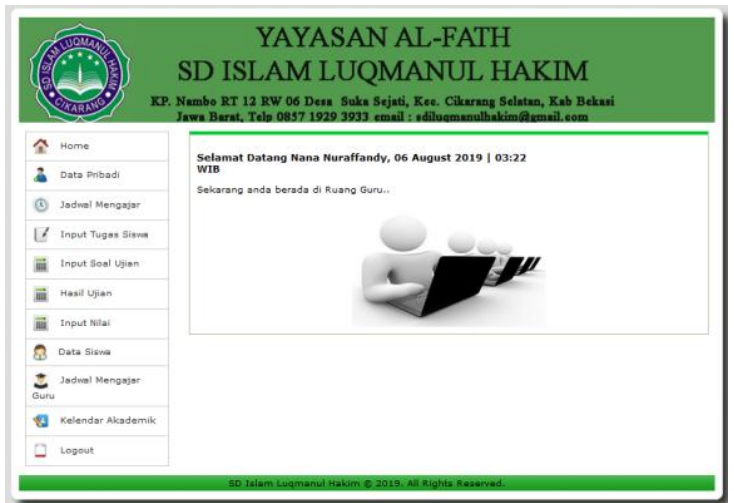

Gambar III.15 Halaman Home Guru

g. Halaman Login Siswa

Siswa melakukan login pada form login dengan memasukkan username dan password untuk masuk ke halaman siswa

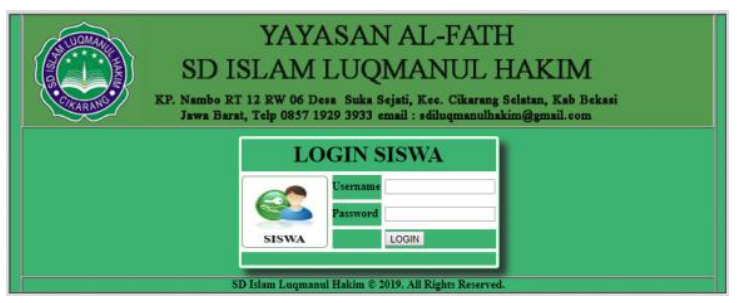

Gambar III.16 Halaman Login Siswa

h. Halaman Home Siswa

Halaman siswa menampilkan beberapa menu yang dapat diakses oleh siswa

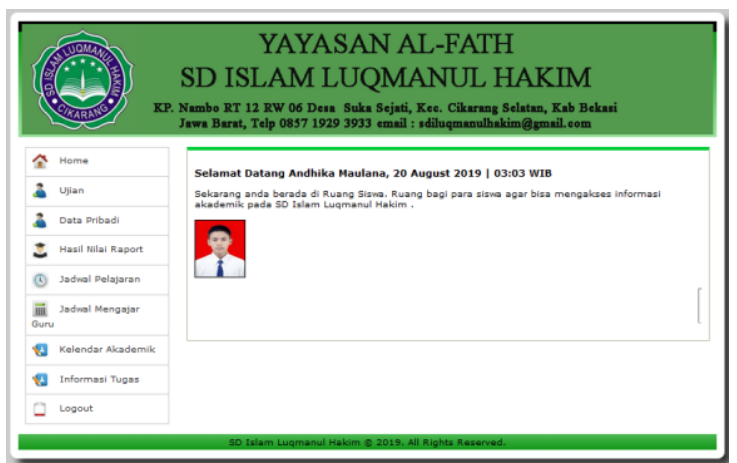

Gambar III.17 Halaman Home Siswa 
DOI: https://doi.org/10.33330/jurteksi.v6i1.399

Available online at http://jurnal.stmikroyal.ac.id/index.php/jurteksi

\section{i. Halaman Login Admin}

Admin melakukan login pada form login admin dengan memasukkan username dan password untuk masuk ke halaman admin

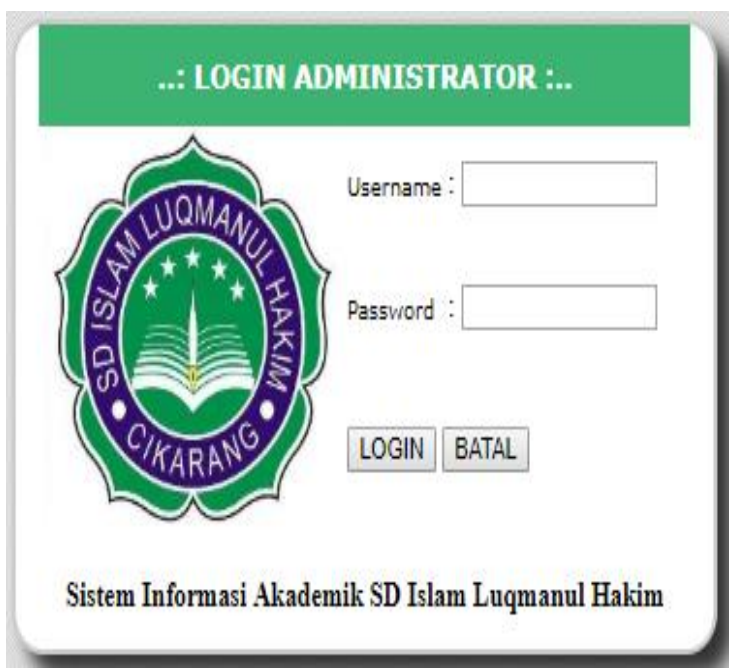

Gambar III.18 Halaman Login Admin

j. Halaman Home Admin

Halaman home admin menampilkan beberapa menu yang bisa diakses oleh admin untuk mengelola back end dari website sekolah

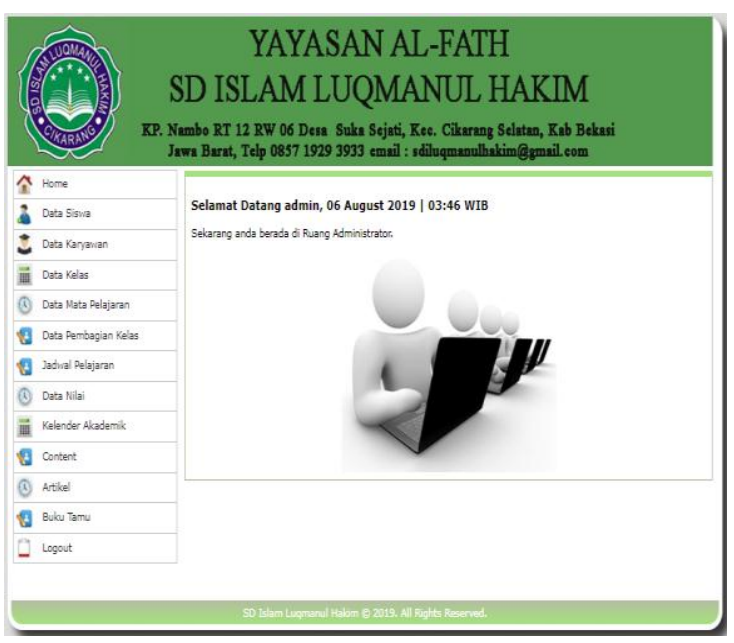

Gambar III.19 Halaman Home Admin

\section{SIMPULAN}

Kesimpulan yang diperoleh setelah melakukan pembuatan Sistem Informasi Akademik Berbasis Website pada SD Islam Luqmanul Hakim ini adalah;

1. Dilihat dari aspek manajerial:

a. Mempermudah pengolahan dan penyimpanan data siswa dan guru.

b. Mempermudah siswa dan orang tua dalam memperoleh informasi akademik.

c. Memberikan informasi profil dan kegiatan sekolah kepada setiap orang yang membuka web sekolah.

2. Dilihat dari aspek sistem:

a. Sebagai sarana informasi yang baik karena sistem sudah berbasis web

b. Informasi akademik bisa diakses kapan saja dan dimana saja

\section{DAFTAR PUSTAKA}

[1] Sari, r. (2016). Sistem informasi akademik berbasis web pada sd negeri 29 jakarta. Jurnal sistem informasi stmik antar bangsa, 4(2), 176-184.

[2] T. Djaelangkara, r., sengkey, r., \& a. Lantang, o. (2015). Perancangan sistem informasi akademik sekolah berbasis web studi kasus sekolah menengah atas kristen 1 tomohon. E-jurnal teknik elektro dan komputer, 160(6), 86-94.

[3] Hasbi, m. (2015). Perancangan sistem informasi akademik pada smk negeri 2 simbang maros 
DOI: https://doi.org/10.33330/jurteksi.v6i1.399

Available online at http://jurnal.stmikroyal.ac.id/index.php/jurteksi

academic information system design on smk state 2 simbang maros. Perancangan sistem informasi akademik pada smk negeri 2 simbang maros, 3(1), 4346.
[4] Purwanto, r., \& supriyono, a. R. (2014). Sentralisasi database penduduk jurnal infotekmesin volume 7 edisi januari 2014 jurnal infotekmesin volume 7 edisi januari 2014. 7, 56-77. 